\title{
Experimental Study on the Treatment of Rural Domestic Wastewater Using the Multi-Soil- Layering System Filled with Sludge-Based Biochar
}

\author{
Jingrui Wang, Zechao Zhang, Ying Guo, Liyong Zhang, Junliang Liu* \\ Urban and Rural Construction Institute, Hebei Agricultural University, Baoding 071000, China
}

Corresponding Author Email: cjljl@ hebau.edu.cn

https://doi.org/10.18280/acsm.450208

Received: 28 November 2020

Accepted: 10 February 2021

\section{Keywords:}

sludge-based biochar, rural domestic wastewater, multi-media soil layering system (MSL), hydraulic loading rate (HLRs), zeolite

\begin{abstract}
This paper aims to improve the treatment effect of the multi-soil-layering system (MSL) on rural domestic wastewater. For this, sludge-based biochar materials were selected in the experiments to study its impacts on the treatment of rural domestic wastewater using the MSL. The comparative experiments were conducted for the three MSL systems filled with different materials: the sludge-based biochar (a), wood chips (b), and charcoal (c). The results showed that when the sludge-based biochar material was used as a filler, the removal effect of COD, $\mathrm{NH}_{4}{ }^{+}-\mathrm{N}, \mathrm{TN}$, TP is better than that of wood chips and charcoal, and the removal rates were $80 \%, 90 \%, 65 \%$ and $92 \%$, respectively, meeting the Grade A standard specified in the Hebei Province Rural Domestic wastewater Discharge Standard (DB13/2171-2015); hydraulic loading rates (HLRs) have a great impact on the removal of pollutants, and the pollutant indicators in the system (a)re affected by the HLRs in different degrees, i.e., $\mathrm{NH}_{4}{ }^{+}-\mathrm{N}>\mathrm{TP}>\mathrm{COD}>\mathrm{TN}$ from high to low; considering the treatment efficiency and pollutant removal effect, the HLRs should be selected between $800 \mathrm{~L} /\left(\mathrm{m}^{2} \cdot \mathrm{d}\right)$ and $1200 \mathrm{~L} /\left(\mathrm{m}^{2} \cdot \mathrm{d}\right)$. It's concluded finally that the sludge-based biochar material can strengthen the removal effect of the MSL system. This study is of theoretical value for the further research on MSL system and resource utilization of the sludge.
\end{abstract}

\section{INTRODUCTION}

Rural domestic wastewater is formed in the daily lives of rural residents, mainly including kitchen wastewater, laundry water, and daily cleaning sewage [1]. It has the characteristics of wide dispersion, large seasonal changes, and low pollutant concentration [2]. Due to large differences of the water quality and quantity between rural and urban domestic wastewater, urban sewage treatment technology is not well applicable to the rural area in terms of both technology and economy [3]. The multi-soil-layering [4] system is a kind of soil purification sewage technology [5] emerging in Japan in the 20th century, which can be used as a good decentralized treatment type [6] of domestic sewage, due to its easy clogging, small space requirement, and low hydraulic loading rate. The MSL system is mainly composed of water-permeable layer and soil mixed layers [7], which mainly removes heavy metals in domestic sewage [8], chemical oxygen demand (COD), ammonia nitrogen $\left(\mathrm{NH}_{4}{ }^{+}-\mathrm{N}\right)$, total nitrogen $(\mathrm{TN})$, total phosphorus (TP) [9] and other pollutants through physical adsorption, exchange, and biological decomposition. Currently some researches have been conducted on treating rural sewage wastewater, restaurant wastewater, polluted river water, but it still needs further study on how to improve the removal effect of pollutants. For this, the authors analyzed the status quo of water quality, water volume and spatial distribution of rural sewage, and studied the use of MLS system to remove the rural domestic wastewater in Hebei Province, to solve the problems in the process of rural sewage treatment.

Sludge-based biochar is the gas and oil produced through the pyrolysis reaction of sludge under anaerobic conditions
[10], as well as the solid residue, namely biochar [11]. Biochar is an environmental functional material with good adsorption [12], rich pore structure, reliable surface properties etc. [13]. It has a certain adsorption effect on heavy metal ions and inorganic pollutants in water [14]. Also, the pore structure of biochar can provide favorable living conditions for aerobic microorganisms in the system to form a biofilm [15], which is beneficial to the removal of pollutants in sewage [16].

The experiments used zeolite as the water-permeable material and sludge-based biochar as the additive material of the soil mixed layer to construct an MSL system. It's aimed to study the removal effect of the system on pollutants and also its stability after changing the hydraulic load.

\section{EXPERIMENTS}

\subsection{Experimental method}

The experiments adopted gravity flow with top in and bottom out and fully submerged continuous flow. The effective volume of the experimental column was about $28 \mathrm{~L}$ and the column height was $1.3 \mathrm{~m}$. From top to bottom, there was $0.2 \mathrm{~m}$ ultra-high and water distribution area, $0.9 \mathrm{~m}$ main reaction area, and $0.2 \mathrm{~m}$ supporting layer and water outlet area. The test water in the water storage tank was lifted by the water inlet pump and entered the experimental column from the top. When passing through the mixed soil layer and the permeable layer, the suspended particles in the water were intercepted and contacted with the filler to form a biofilm [17]. The raw water was then discharged from the bottom after digestion and decomposition of the biofilm. 


\subsection{Test wastewater quality}

Table 1. Test wastewater quality

\begin{tabular}{cc}
\hline Test Indicators & Range \\
\hline $\mathrm{pH}$ & $6.0-8.0$ \\
$\mathrm{COD}(\mathrm{mg} / \mathrm{L})$ & $80-300$ \\
$\mathrm{NH}_{4}^{+} \mathrm{-N}(\mathrm{mg} / \mathrm{L})$ & $10-40$ \\
$\mathrm{TN}(\mathrm{mg} / \mathrm{L})$ & $15-50$ \\
$\mathrm{TP}(\mathrm{mg} / \mathrm{L})$ & $1.0-5.0$ \\
\hline
\end{tabular}

In view of the characteristics of rural domestic wastewater quality, the concentration range of inlet water's $\mathrm{COD}, \mathrm{NH}_{4}+-$ $\mathrm{N}, \mathrm{TN}, \mathrm{TP}$ was finally determined, as shown in Table 1.

\subsection{Experimental materials}

The MSL system is mainly composed of soil mixed layer and permeable layer. Natural soil was used in the mixed layer; sludge-based biochar, wood chips, charcoal and iron chips were also added according to the experimental design. Zeolite was selected for the permeable layer as the filler. The material composition of the three systems is shown in Table 2.

\subsection{Sampling and analysis methods}

During the system operation, samples were taken regularly every day to analyze the inlet and outlet water quality. Table 3 lists testing indicators and methods.

Table 2. System components

\begin{tabular}{cccccc}
\hline \multirow{2}{*}{ System } & \multirow{2}{*}{ Permeable layer } & \multicolumn{5}{c}{ The proportion of the dry mass of each constituent material in the mixed soil layer } \\
& Natural soil & Iron chips & Sludge-based biochar & Wood chips & Charcoal \\
\hline a & Zeolite & 7 & 1 & & \\
b & Zeolite & 7 & 1 & & 2 \\
$\mathrm{c}$ & Zeolite & 7 & 1 & & 2 \\
\hline
\end{tabular}

Table 3. Main testing instruments and analytical methods

\begin{tabular}{ccc}
\hline Test Items & Test Methods & Instruments \\
\hline $\mathrm{COD}$ & Potassium Dichromate Colorimetry & Reflux device and titration device \\
$\mathrm{NH}_{4}{ }^{+}-\mathrm{N}$ & Nessler's reagent spectrophotometry & Spectrophotometer/Hash DR5000 \\
TP & Ammonium molybdate spectrophotometry & Spectrophotometer/Hash DR5000 \\
TN & Potassium persulfate oxidation-ultraviolet spectrophotometry & Spectrophotometer/Hash DR5000 \\
DO & Instrument direct reading & Portable dissolved oxygen meter/JPSJ-608 \\
Microbial Morphology & Direct observation & Trinocular Biological Microscope/UB100i \\
\hline
\end{tabular}

\section{RESULTS AND DISCUSSION}

\subsection{Removal effect on different components}

\subsubsection{COD removal effect}

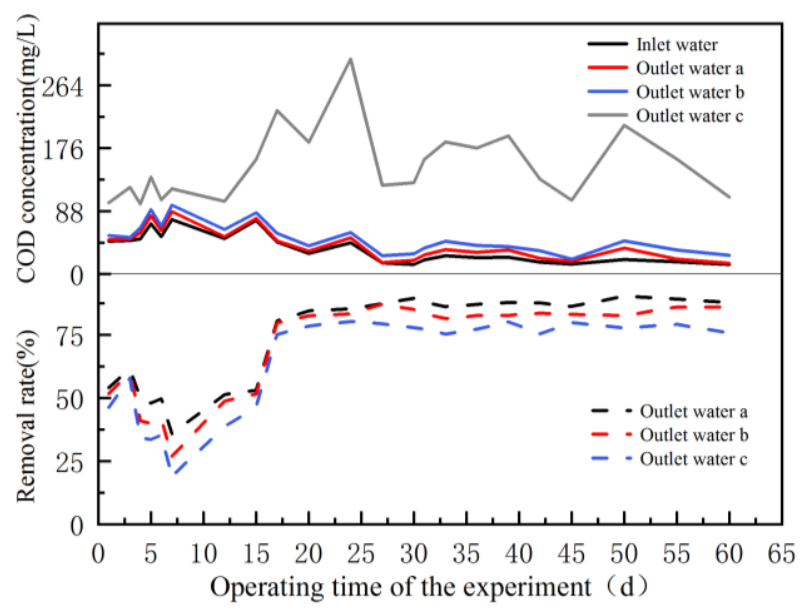

Figure 1. Removal effect of COD

Figure 1 shows that the removal rates of COD by the three systems all first dropped and then rose, and finally stabilized. For the system (a), the COD removal rate basically tended to be stable above $80 \%$ after the 17 th day, and the COD concentration of outlet water was also below $50 \mathrm{mg} / \mathrm{L}$, which meets the Grade-A standard specified in Hebei Province Rural Domestic Wastewater Discharge Standard (DB13/2171-2015).
The removal rate of the system (a) is significantly higher than that of (b) and (c) systems. At the initial stage of the test, the COD in the raw water was mainly removed due to the physical barrier and chemical adsorption of the permeable layer and the mixed soil layer; with the formation of the biofilm, it is mainly the adsorption and decomposition of microorganisms [18]. Through comprehensive analysis of the COD removal effect, it's concluded that the removal effect of system (a) is better than the (b) and (c) systems because of its fast biofilm formation and stable operation.

\subsection{2 $\mathrm{NH}_{4}+-\mathrm{N}$ removal effect}

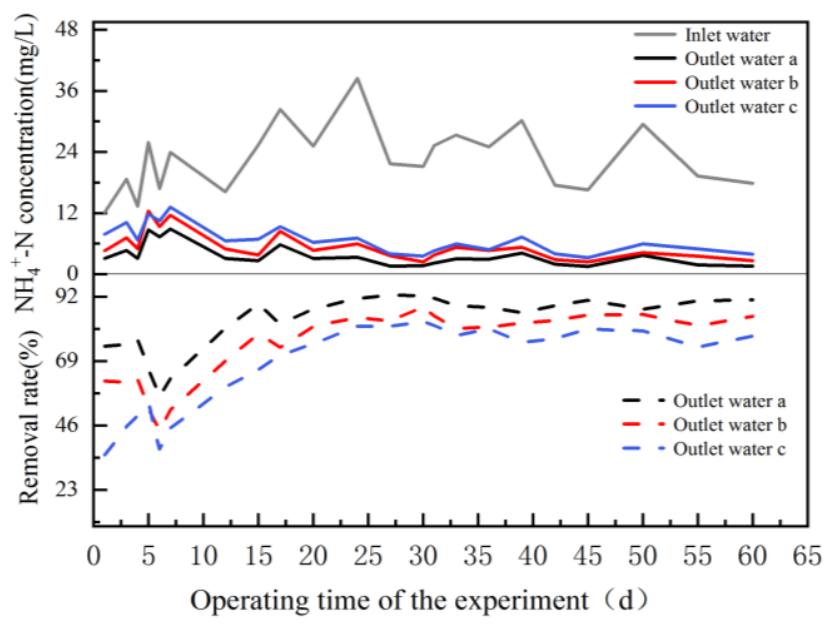

Figure 2. Removal effect of $\mathrm{NH}_{4}{ }^{+}-\mathrm{N}$ 
Figure 2 shows that the removal rate of the system (a) is relatively high at the initial stage of operation, mainly due to the adsorption of sludge-based biochar in the mixed soil layer. After reaching saturation, its removal rate was reduced to a minimum. Finally, the removal rate of $\mathrm{NH}_{4}{ }^{+}-\mathrm{N}$ by the system increased through nitrification until it remains stable. After the 27th day, the removal rate of $\mathrm{NH}_{4}{ }^{+}-\mathrm{N}$ by the system (a) basically stabilized, basically up to more than $90 \%$, and the $\mathrm{NH}_{4}{ }^{+}-\mathrm{N}$ of the outlet water was below $5 \mathrm{mg} / \mathrm{L}$, meeting the Grade-A standard of the Hebei Province Rural Domestic Wastewater Discharge Standard (DB13/2171-2015). For the systems (b) and (c), the removal efficiency of $\mathrm{NH}_{4}{ }^{+}-\mathrm{N}$ was slightly poor, with a removal rate of about $80 \%$, because of the insufficient oxygen content in the systems and poor nitrification.

\subsubsection{TN removal effect}

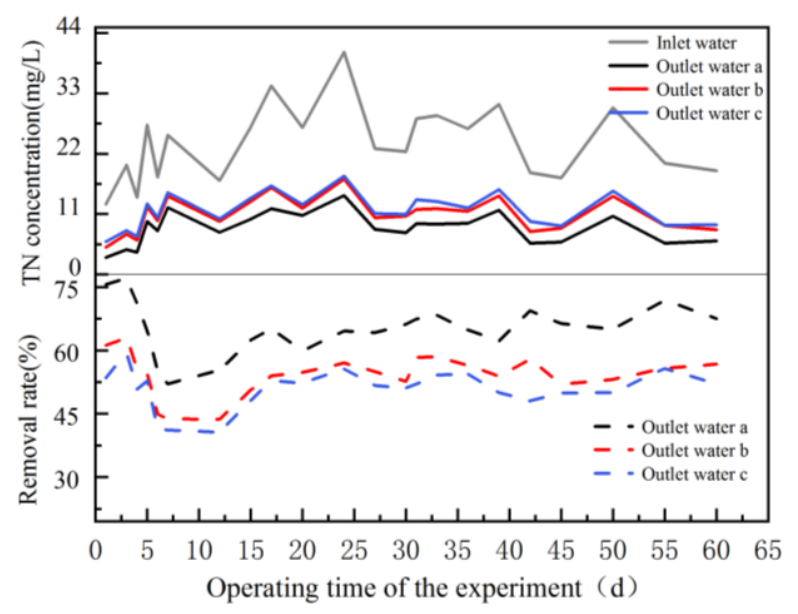

Figure 3. Removal effect of TN

Figure 3 shows that the removal rate of the system (a) was relatively high at the initial stage of operation, mainly due to the adsorption of sludge-based biochar in the mixed soil layer; after reaching saturation, the removal rate was reduced to the minimum. The system finally reduced the TN removal rate through nitrification and denitrification until it remained stable. After the 27 th day, the removal rate of TN by the system (a) basically stabilized above $65 \%$, and the TN of the outlet water was basically below $10 \mathrm{mg} / \mathrm{L}$. The three systems all have poor removal effects on $\mathrm{TN}$, with a removal rate below 70 . This should be due to the effect of the nitrification and denitrification and the balance of oxygen in the systems, which restricts the removal of nitrogen.

\subsubsection{TP removal effect}

Figure 4 shows that the removal effect of the three systems on TP is relatively stable. The TP removal rate of the stabilized system (a) was about $92 \%$, and that for the (b) and (c) was $88 \%$ and $82 \%$, respectively. The system (a) has a good removal effect on TP, and the TP concentration of the outlet water is stabilized below $1 \mathrm{mg} / \mathrm{L}$, which satisfies the emission requirements. Through comprehensive analysis, it's found that the removal of TP by the system is mainly due to the physical and chemical effects in the mixed soil layer. The phosphate in the raw water oxidizes the iron in the mixed soil layer to divalent iron, which is further oxidized to iron hydroxide in the permeable layer, and finally removed in the forms of precipitation and complex compound.

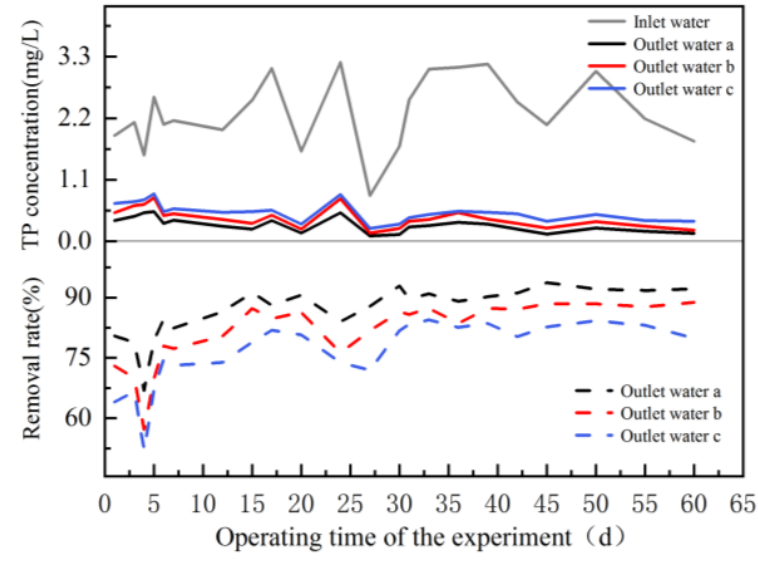

Figure 4. Removal effect of TP

\subsection{Impacts of HLRs on removal effect of pollutants}

With other parameters unchanged, the tests were conducted under the inlet water's HLRs of $400 \mathrm{~L} /\left(\mathrm{m}^{2} \cdot \mathrm{d}\right), 800 \mathrm{~L} /\left(\mathrm{m}^{2} \cdot \mathrm{d}\right)$, $1200 \mathrm{~L} /\left(\mathrm{m}^{2} \cdot \mathrm{d}\right), 1500 \mathrm{~L} /\left(\mathrm{m}^{2} \cdot \mathrm{d}\right)$ and $2000 \mathrm{~L} /\left(\mathrm{m}^{2} \cdot \mathrm{d}\right)$ respectively, to compare and analyze the removal effect of COD, NH4+-N, $\mathrm{TN}$ and TP under different hydraulic loads.

\subsubsection{The impact of the HLRs on COD removal rate}

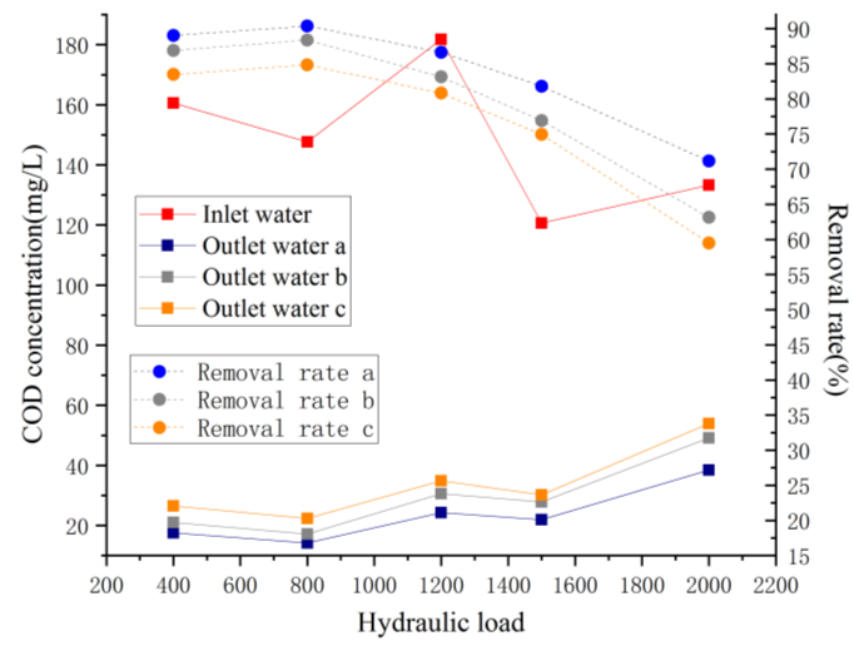

Figure 5. Impact of the HLRs on COD removal rate

It can be seen from Figure 5 that for the three systems, the COD removal rates all decreased with the increase of HLRs. When HLRs were between $400 \mathrm{~L} /\left(\mathrm{m}^{2} \cdot \mathrm{d}\right)$ and $1200 \mathrm{~L} /\left(\mathrm{m}^{2} \cdot \mathrm{d}\right)$, the average removal rate of COD by system (a) was above $85 \%$, and the COD concentration of outlet water was less than $50 \mathrm{mg} / \mathrm{L}$. When HLRs increased from $1200 \mathrm{~L} /(\mathrm{m} 2 \cdot \mathrm{d})$ to $2000 \mathrm{~L} /(\mathrm{m} 2 \cdot \mathrm{d})$, the removal rate of COD in system (a) decreased by $15.49 \%$, and the COD concentration of outlet water increased. Considering system water volume, treatment efficiency, and operating cost, HLRs between $800 \mathrm{~L} /\left(\mathrm{m}^{2} \cdot \mathrm{d}\right)$ and $1200 \mathrm{~L} /\left(\mathrm{m}^{2} \cdot \mathrm{d}\right)$ should be selected.

\subsubsection{The impact of the HLRs on the removal rate of $\mathrm{NH}_{4}{ }^{+}-\mathrm{N}$}

Figure 6 shows that when the HLRs was $800 \mathrm{~L} /\left(\mathrm{m}^{2} \cdot \mathrm{d}\right)$, the removal rates of $\mathrm{NH}_{4}{ }^{+}-\mathrm{N}$ by the three systems were $90.01 \%$, $84.01 \%$, and $79.81 \%$, respectively, and the ammonia nitrogen concentration in the outlet water was $1.95 \mathrm{mg} / \mathrm{L}, 3.12 \mathrm{mg} / \mathrm{L}$ and $3.94 \mathrm{mg} / \mathrm{L}$. When HLRs increased from $1200 \mathrm{~L} /\left(\mathrm{m}^{2} \cdot \mathrm{d}\right)$ to 
$2000 \mathrm{~L} /\left(\mathrm{m}^{2} \cdot \mathrm{d}\right)$, the removal rate of $\mathrm{NH}_{4}{ }^{+}-\mathrm{N}$ by the three systems decreased by $33.71 \%, 34.73 \%$ and $34.13 \%$, respectively. This is because the changes with the hydraulic load of the system have affected the reoxygenation and changed the conditions of nitrification and denitrification.

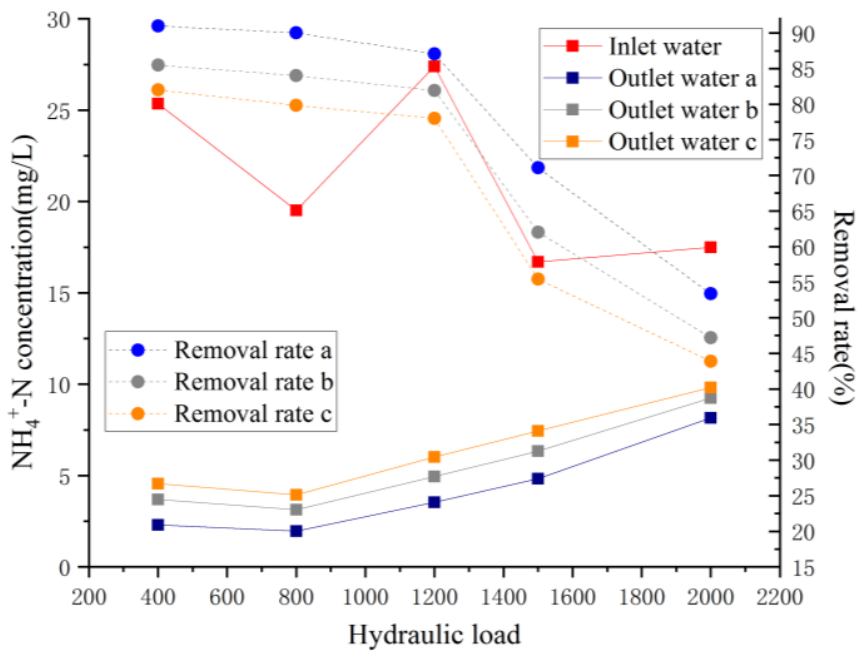

Figure 6. Impact of the HLRs on $\mathrm{NH}_{4}{ }^{+}-\mathrm{N}$ removal rate

3.2.3 The impact of the HLRs on TN removal rate

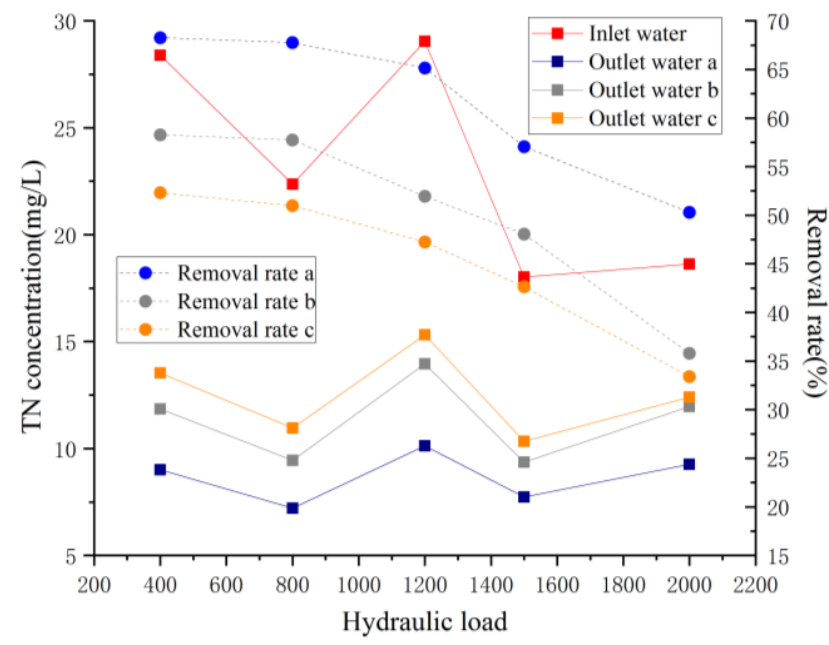

Figure 7. Impact of the HLRs on TN removal rate

It can be seen from Figure 7 that when the HLRs was $800 \mathrm{~L} /\left(\mathrm{m}^{2} \cdot \mathrm{d}\right)$, the removal rates of $\mathrm{TN}$ by the three systems were $67.75 \%, 57.74 \%$, and $50.98 \%$, respectively, and the TN concentrations of the effluent were $7.21 \mathrm{mg} / \mathrm{L}, 9.45 \mathrm{mg} / \mathrm{L}$ and $10.96 \mathrm{mg} / \mathrm{L}$. When HLRs increased from $1200 \mathrm{~L} /\left(\mathrm{m}^{2} \cdot \mathrm{d}\right)$ to $2000 \mathrm{~L} /\left(\mathrm{m}^{2} \cdot \mathrm{d}\right)$, the removal rate of $\mathrm{TN}$ by them decreased by $14.85 \%, 16.13 \%$ and $13.86 \%$ respectively. The reason should be the changes of oxygen balance in the system which have changed the conditions of nitrification and denitrification, and made it difficult to remove nitrogen.

\subsubsection{The impact of the HLRs on TP removal rate}

Figure 8 shows that the removal rate of TP by the three systems decreases with the increase of HLRs. When the HLRs were $800 \mathrm{~L} /\left(\mathrm{m}^{2} \cdot \mathrm{d}\right)$, the average removal rates of TP by the three systems were $90.98 \%, 87.45 \%$, and $83.14 \%$, respectively, and the TP concentration of the effluent was less than $0.5 \mathrm{mg} / \mathrm{L}$. When HLRs increased from $1200 \mathrm{~L} /\left(\mathrm{m}^{2} \cdot \mathrm{d}\right)$ to $2000 \mathrm{~L} /\left(\mathrm{m}^{2} \cdot \mathrm{d}\right)$, the removal rate of the TP by the systems $a, b$, and c decreased rapidly by $15.9 \%, 19.27 \%$, and $22.42 \%$, respectively. Overall, the system (a) has a better removal effect on TP, but when the hydraulic load is increased, the oxygen content in the system decreases, which affects the formation of strong adsorbents (complexes of iron, aluminum, calcium, etc.), and mitigates the removal effect of phosphorus.

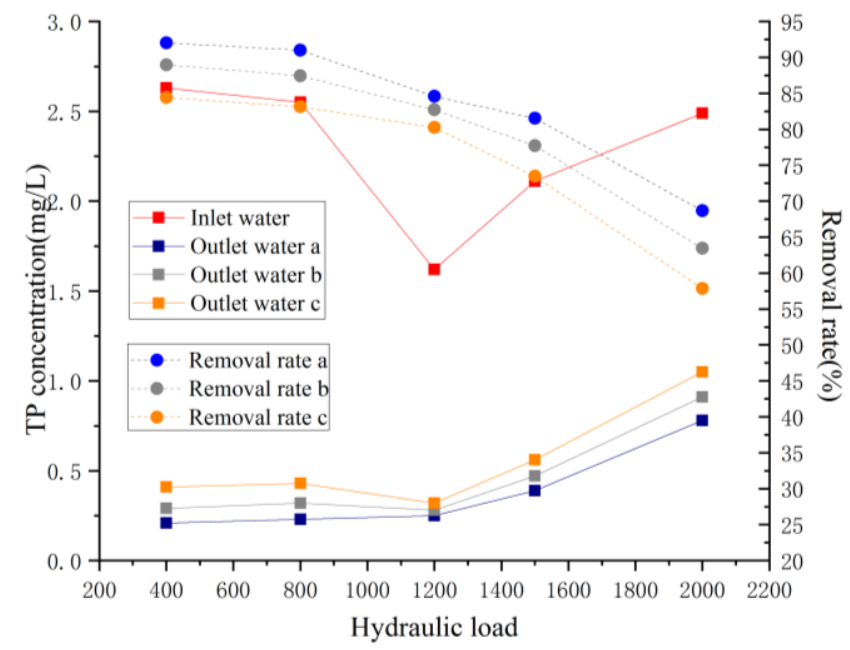

Figure 8. Impact of the HLRs on TP removal rate

\section{CONCLUSIONS}

(1) The experiments indicate that the system (a) has the best removal effect on pollutants in rural domestic wastewater, enjoys better effluent quality, and operates more stably due to its fast biofilm culturing. After stable operation of the system (a), the average removal rates of COD, NH4+-N, TN and TP were $88.35 \%, 89.74 \%, 68.12 \%$ and $92.16 \%$, respectively.

(2) Hydraulic loading rates (HLRs) have great impacts on the removal effect of pollutants. The removal effect of each pollutant decreases with the increase of HLRs, especially NH4+-N and TP. In the experiments, the impact degree of HLRs on different components was ranked as NH4+$\mathrm{N}>\mathrm{TP}>\mathrm{COD}>\mathrm{TN}$ from high to low. Considering the treatment efficiency and water volume, the inlet water HLRs of the system between $800 \mathrm{~L} /\left(\mathrm{m}^{2} \cdot \mathrm{d}\right)$ and $1200 \mathrm{~L} /\left(\mathrm{m}^{2} \cdot \mathrm{d}\right)$ should be selected.

\section{ACKNOWLEDGEMENTS}

This paper was supported by Hebei Province Talents Training Project (Grant No.: A201901047) and Science and Technology Foundation of Agricultural University of Hebei (Grant No.: LG201631).

\section{REFERENCES}

[1] Hu, M., Liu, J.H., Zhu, S.K., Li, G.J., Qu, B., Fan, B. (2015). Assessment of rural decentralized sewage treatment technology. China Water \& Wastewater, 31(12): 16-21.

[2] Miao, J., Ji, C. Gao, L.L., Fang, X.J. (2020). Estimation and significance of the peak variation factor of rural domestic sewage quantity in China. Chinese Journal of 
Environmental Engineering, 14(9): 2326-2330. https://doi.org/10.12030/j.cjee.202001107

[3] Yuan, H.P., Nie, J.Y., Zhu, N.W. (2013). Case study on treatment engineering of rural domestic sewage. China Water \& Wastewater, 29(21): 72-74.

[4] Wakatsuki, T., Omura, S., Abe, Y., Izumi, K., Matsui, Y. (1990). Treatment of domestic waste water by multi-soillayering system (Part 3): Role and life of purification abilities of soil materials in the systems. Japanese Journal of Soil Science and Plant Nutrition, 61(1): 74-84. https://doi.org/10.20710/dojo.61.1_74

[5] Shen, J., Huang, G., An, C., Song, P., Xin, X., Yao, Y., Zheng, R. (2018). Biophysiological and factorial analyses in the treatment of rural domestic wastewater using multi-soil-layering systems. Journal of Environmental Management, 226: 83-94. https://doi.org/10.1016/j.jenvman.2018.08.001

[6] Song, P., Huang, G., Hong, Y., An, C., Xin, X., Zhang, P. (2020). A biophysiological perspective on enhanced nitrate removal from decentralized domestic sewage using gravitational-flow multi-soil-layering systems. Chemosphere, 240: 124868. https://doi.org/10.1016/j.chemosphere.2019.124868

[7] Ho, C.C., Wang, P.H. (2015). Efficiency of a multi-soillayering system on wastewater treatment using environment-friendly filter materials. International Journal of Environmental Research and Public Health, 12(3):

3362-3380. https://doi.org/10.3390/ijerph120303362

[8] Wakatsuki, T., Omura, S., Abe, Y., Izumi, K. (1989). Treatment of domestic waste water by multi-soillayering system (Part2): Relation of fluctuation of temperature, flow-out rate of treated water, $\mathrm{pH}$, iron and manganese concentrations to the efficiency of the system. Japanese Journal of Soil Science and Plant Nutrition, 60(4): 345-351. https://doi.org/10.20710/dojo.60.4_345

[9] Sato, K., Iwashima, N., Wakatsuki, T., Masunaga, T. (2011). Quantitative evaluation of treatment processes and mechanisms of organic matter, phosphorus, and nitrogen removal in a multi-soil-layering system. Soil Science and Plant Nutrition, 57(3): 475-486. https://doi.org/10.1080/00380768.2011.590944

[10] Racek, J., Sevcik, J., Chorazy, T., Kucerik, J., Hlavinek, P. (2020). Biochar-recovery material from pyrolysis of sewage sludge: A review. Waste and Biomass Valorization, $\quad$ 11(7): $\quad 3677-3709$. https://doi.org/10.1007/s12649-019-00679-w

[11] Bao, D., Li, Z., Tang, R., Wan, C., Zhang, C., Tan, X., Liu, X. (2021). Metal-modified sludge-based biochar enhance catalytic capacity: Characteristics and mechanism. Journal of Environmental Management, 284: 112113. https://doi.org/10.1016/j.jenvman.2021.112113

[12] Xie, C., Yuan, L., Tan, H., Zhang, Y., Zhao, M., Jia, Y. (2021). Experimental study on the water purification performance of biochar-modified pervious concrete. Construction and Building Materials, 285: 122767. https://doi.org/10.1016/j.conbuildmat.2021.122767

[13] Munir, M.A.M., Yousaf, B., Ali, M.U., Dan, C., Abbas, Q., Arif, M., Yang, X. (2021). In situ synthesis of microplastics embedded sewage-sludge co-pyrolyzed biochar: Implications for the remediation of $\mathrm{Cr}$ and $\mathrm{Pb}$ availability and enzymatic activities from the contaminated soil. Journal of Cleaner Production, 302: 127005. https://doi.org/10.1016/j.jclepro.2021.127005

[14] Zang, T., Wang, H., Liu, Y., Dai, L., Zhou, S., Ai, S. (2020). Fe-doped biochar derived from waste sludge for degradation of rhodamine $\mathrm{B}$ via enhancing activation of peroxymonosulfate. Chemosphere, 261: 127616. https://doi.org/10.1016/j.chemosphere.2020.127616

[15] Regkouzas, P., Diamadopoulos, E. (2019). Adsorption of selected organic micro-pollutants on sewage sludge biochar. Chemosphere, 224: 840-851. https://doi.org/10.1016/j.chemosphere.2019.02.165

[16] Gopinath, A., Divyapriya, G., Srivastava, V., Laiju, A.R., Nidheesh, P.V., Kumar, M.S. (2021). Conversion of sewage sludge into biochar: A potential resource in water and wastewater treatment. Environmental Research, 194: 110656. https://doi.org/10.1016/j.envres.2020.110656

[17] Hong, Y., Huang, G., An, C., Song, P., Xin, X., Chen, X., Zhang, P., Zhao, Y., Zheng, R. (2019). Enhanced nitrogen removal in the treatment of rural domestic sewage using vertical-flow multi-soil-layering systems: Experimental and modeling insights. Journal of Environmental Management, 240: 273-284. https://doi.org/10.1016/j.jenvman.2019.03.097

[18] Song, P., Huang, G., An, C., Shen, J., Zhang, P., Chen, X., Yao, Y., Zheng, R., Sun, C. (2018). Treatment of rural domestic wastewater using multi-soil-layering systems: Performance evaluation, factorial analysis and numerical modeling. Science of the Total Environment, 644: 536-546. 